\title{
The Relocation of Monstrosity: An Analysis of Horror in Brian De Palma's Carrie
}

\author{
Mike Thorn
}

Brian De Palma's Carrie functions within the horror genre's framework in two prominent ways: first, it includes a monstrous subject, and second, it associates generically typical traits with monstrosity. In the film's conclusion, the monstrous subject is embodied by the title character, Carrie, who manifests monstrous tropes of sexual anxiety and supernatural abilities. However, other manifestations of monstrosity in the film are less typical. Its subversive approach to the horror genre is initially visible through Carrie's relationship with society (contextually embodied by her mother and her classmates). The first two acts of the film present the normalized social body as the monstrous subject, accordingly positioning Carrie as the victimized protagonist. The third act relocates monstrosity to Carrie, animating audience empathy with her violent reaction. This crucial shift is atypical of the genre if film critic Steven Neale's assertion that "the monster is difference made flesh" is understood to be true (Neale 99). In fact, the film completely reconfigures Neale's assertion, so that monstrosity is malleable and socially-constructed. The normalized group that surrounds Carrie is, initially, the locus of monstrosity, victimizing difference rather than representing it. At this juncture, monstrosity is portrayed in the film as the prejudiced imposition of social normativities. The film examines its genre's traditional representation of monstrosity as a visibly horrific threat, reconstructing it as the invisible violence of social judgment.

If the monster is defined broadly by a "kind of alterity," the film's first two acts are unusual (Neale 99). That is, Carrie's otherness is not exploited as a source of horror until the conclusion; instead, it is her mother and the normalized social group at high school who operate as catalysts of fear. Although this dynamic aligns with the belief that "the categories 'human' and 'monster' are coincident [and] mutually constitutive," it also opposes the notion of monstrosity as a subject of alterity (Neale 99). Perhaps the reaction to Carrie's supernatural qualities can be described as an example of fear motivated by difference, but the concept is challenged and even subverted in some ways. The clearest of these subversions is that the protagonist, Carrie, cannot easily be characterized as "the other." As such, the audience is motivated to empathize and relate with her on some level. Furthermore, the high school's social body cannot be labelled as difference-made flesh, since it is represented as a normative collective unit.

The film's depiction of high school bullying both aligns with and opposes a traditional definition of horror. The opening sequence, which takes place in the school gymnasium girls' shower, is particularly noteworthy. The scene begins with a hypnagogic, slow motion wide shot, which is clouded with enough shower steam to evoke a surreal atmosphere. The camera pans across Carrie's female classmates in the change room, then tracks toward Carrie from behind; she is isolated in a plume of smoke, her body softly framed by low-key lighting. The scene's dreamlike quality is amplified by close-up shots emphasizing Carrie's subjective sensory enjoyment. Fade-outs link repetitious close-ups of the soap, the showerhead, and Carrie's body, with evident intent to lull the audience into submission. A final close-up disrupts the scene's rhythm: framing a stream of blood 
trickling down Carrie's leg. Carrie's reaction to her first menstrual experience is shot in similarly intimate perimeters before the scene cuts to her classmates, who are still laughing and socializing in the well-lit change room.

Although Barbara Creed interprets the scene as an expression of "women's sexuality as the source of all evil and menstruation as the sign of sin," the episode is more importantly depicted from Carrie's perspective, with her classmates filmed separately as an external threat (Creed 74). The decision to do so aligns with Stephen King's assertion that the greatest horror facing high school students is the "fear of being afraid and not being able to tell anyone [they're] afraid" (King 1988, 90). ${ }^{1}$ With this concept in mind, Carrie embodies a relatable role as a high school teenager. More importantly, she is situated as a subject of sympathy for the audience and, consequently, opposition to her peers' reactions is encouraged. Her perspective is captured first in a hand-held tracking shot: Carrie is followed from behind as she rushes toward her classmates, pleading for help. The scene regresses into collective monstrosity, depicted with Carrie's dizzying point-of-view shot: a swarm of normatively attractive girls hurl tampons at her, backing her into a wall and telling her to "plug it up" in a cruel and persistent chant. Carrie collapses with terror into the corner, occupying the position of a victim. Her expression of fear is again captured here in close-up, allowing the audience to empathize with her anguish on an immediate and intimate level. As a result, the scene characterizes Carrie as a pitiable protagonist, while the normalized social body becomes the other.

The portrait of sexual maturation as a platform for horror matches the theory that "modern horror myths prepare the teenager for the anxieties of reproduction" (Neale 98). However, it is not Carrie's menstruation that operates as the scene's subject of horror; rather, it is her peers' uniformly malicious response. The scene's representation of the social body is deliberate in its intentions. King argues that "teenagers are the most conservative people in American society" (King 1988,16). With this notion in mind, it is not Carrie's unknowing that prompts a horrified response from the audience. Instead, the socially-collective condemnation of her individual sexuality incites fear. The film uses teenage sexuality as a vessel to explore anxiety and social oppression.

It also expands the perimeters of cruelty by portraying Carrie's mother as a monstrous figure; she is introduced with an ominous, stationary wide shot from behind, her black cape flapping behind her in a way that evokes popular images of Dracula. By portraying Carrie's mother as a menacing threat, the film further challenges the notion of monstrosity as a subject of alterity. Carrie is not offered a place of solace or escape; instead, social brutality is reaffirmed by her mother's religiously fanatical behaviour. Her mother interprets menstruation as God's punishment for sin and abuses Carrie accordingly. The scenes of domestic brutality are depicted similarly to the aforementioned shower sequence, focusing intently on Carrie's perspective. Consequently, the audience is stationed in a position of closeness and emotional recognition.

When Carrie is first locked in the closet, she is not portrayed as the embodiment of difference. Instead, her mother's use of Christian doctrine as a justification for violence creates a sense of fear. The closet scene is shot in claustrophobic closeness with minimal light; it begins with a medium overhead shot, which illuminates Carrie as a victim to higher powers. A deformed statue of a bleeding Christ is filmed in an eerie medium shot, its aura

\footnotetext{
${ }^{1}$ The film is based on King's novel, Carrie.
} 
intensified by low-key candlelight. The scene's domestic terror is further underlined by strategic use of Pino Donaggio's grating musical score. At this point, Carrie's mother becomes the film's subject of monstrosity, but she operates dually as the prominent figure of domesticity and a threat to Carrie. Thus, she is part of the film's dualistic focus on monstrosity. Aligning with its atypical approach to horror, she is not the sole source of fear. Instead, she is one of several subjects embodying the perpetually-relocated and ubiquitous presence of terror.

The dualism of horror and monstrosity is most explicitly personified by Carrie in the film's final act. Worth noting, however, is the fact that the violence of the climactic prom scene is activated by Carrie's socially elite peers, Chris and her abusive boyfriend, Billy. In an earlier scene, Billy embodies the monster, beating a pig to death for the purpose of his vindictive prank. The scene is introduced with a wide-shot facing the wall of a pigpen. Billy's shadow, and the shadows of his friends, trace up the wall with dramatic, expressionist height. Billy is framed in the pigpen with a medium shot; he raises his hammer over his head and, as he brings it down, the film cuts to an ominous wide-shot of Carrie's lightning-lit house. After the brief, twenty-second shot, the scene cuts to a religious mural that belongs to Carrie's mother. The alignment of Billy's violence with aggressivelyused Christian imagery effectively links the two parties as monstrous figures. Later, Billy's collected bucket of blood operates as an object to qualify fear; when the blood leaves Billy's hands and spills on Carrie's head, horror is transported simultaneously.

When Chris and Billy dump a bucket of pig's blood on Carrie's head, it serves as a catalyst for her supernatural rampage. Consequently, it serves as a catalyst for the film's horror. The prom massacre is edited with a split-screen effect, viscerally depicting the divided and multi-faceted quality of monstrosity. Carrie's wide-eyed, blood-spattered face is framed in close-up with low-key, shadowy red light. In the other split-screen panels, her victims flee as they are terrorized by the animations of her telekinesis. The film's progression allows room for the audience to empathize with Carrie's reaction without necessarily endorsing it.

However, the events of the prom are gruesome in nature and effectively serve as a platform for the attribution of monstrosity. Carrie becomes embodied difference at this point, but she is qualified as such by the blood splattered over her body. The subjects who marked her as a monster are the motivators of the incident; their cruelty qualifies as a form of monstrosity in itself. As a result, the prom scene enacts the notion of alterity as a ubiquitous presence. Every subject contributes to the activation of the scene's horror; both the social body and Carrie are guilty of violence, perhaps the former more than the latter. Creed interprets the portrait of "pig's blood [running] down Carrie's body at a moment of intense pleasure" as a visual articulation of the offensive simile of "women bleed[ing] like pigs" (Creed 74). However, the scene portrays the destruction caused by sexual repression in a negative way. The prom scene demonstrates a moment-by-moment relocation of monstrosity.

Carrie's multiple embodiments of monstrosity are emphasized by King's description of its embattled subjects. He describes an "image of a bear being baited by a bunch of dogs that [are] snarling and biting . . . at her" (King 1988, 86). With this visualization, he imagines Carrie and her peers as both perpetrators and victims. Carrie is represented by the larger animal, but the social body is larger in number and the first to take action. The 
depiction of both subjects as (potentially) dangerous animals re-emphasizes the ubiquity of monstrosity, stationing every character as a source of possible violence.

Carrie's examination of horror as a permeating force enhances the suggestions of its final scene. Taking the analysis of pervasive monstrosity into account, the conclusion functions both inside and outside horror's generic conventions. Specifically, it complicates the idea that "the monster is (perhaps) destroyed and order (perhaps) restored" (Neale 97). The scene portrays Carrie's peer, Sue, approaching Carrie's vandalized grave with flowers. The scene begins with a slow, languid tracking shot, paradoxically disarming and triggering the audience's expectation for further terror. The peak of the scene depicts Carrie's arm bursting through the ground to seize Sue by the wrist. The film ends with Sue struggling while her mother tries to pull her away. The scene verifies that monstrosity has not been effaced.

The first evidence of persisting monstrosity is visible on Carrie's defaced gravestone; the words "Carrie White burns in hell" are framed in a tight close-up. The inclusion of this detail reaffirms the persistence of social monstrosity, both through religious fanaticism and normative oppression. The social body, which earlier animated the pivotal scene of horror, is still characterized by cruelty and malice. Carrie, initially the victim and protagonist, has now fully embodied the position of alterity. Depicted as a zombie-like subject, she reaches through the dirt and violates her classmate's deluded sense of peace. Here, King's suggestion that people watch horror films "to get rid of" their fears is challenged (King 1988, 89). That is, his notion positions the horror film as a mode of catharsis, which effectively qualifies Carrie as an atypical example. At the conclusion, the audience is not "rid of" Carrie, nor are they "rid of" the qualities that animate violence in subjects represented by Carrie.

Carrie is atypical of its generic conventions because it does not identify monstrosity with a single subject. Its representation of the normalized social group as a monstrous presence is an even more noteworthy example of formal deviation. In reference to horror cinema, David Pirie argues, "our fears are among the most revealing things about us" (Pirie 224). This consideration raises complex and unusual issues in reference to Carrie. If the character Carrie is the audience's fear embodied, the source of her terrorism must be scrutinized. The film makes an inextricable link between her violent actions and the people motivating them. As a result, the audience is called to question itself and even motivated to fear itself. The presence and expression of monstrosity, violence, and terror confirm Carrie's status as a horror film. It is traditional in its use of visual cues such as darkness, blood and abnormality as sources of fear. In this sense, it obeys the conventions of its genre and embraces its iconography. However, the initially normative and ultimately transformative examination of monstrosity makes it an atypical horror film. The protagonist's normalized environment is revealed to be a sinister setting. Carrie's alterity is not inherently terrifying; she is pushed to terrifying measures by the social body that victimizes her. 
Works Cited

Carrie. Dir. Brian De Palma. MGM, 1976. DVD.

Creed, Barbara. The Monstrous Feminine: Film, Feminism, Psychoanalysis. London: Routledge, 1993. Print.

King, Stephen. Bare Bones: Conversations on Terror with Stephen King. Ed. Tim Underwood and Chuck Miller. New York: Warner Books, 1988. Print.

King, Stephen. Carrie. New York: Pocket Books, 1974. Print.

Neale, Steve. Genre and Hollywood. London: Routledge, 2009. Print.

Pirie, David. A New Heritage of Horror: The English Gothic Cinema. London: I.B. Tauris, 2008. Print. 